\title{
Treatment of anterior vaginal wall prolapse with and without polypropylene mesh: a prospective, randomized and controlled trial - Part II
}

José Tadeu Nunes Tamanini, Renata Cristina de Oliveira Souza Castro, Juliana Milhomem Tamanini, Paulo Cezar Feldner Jr, Rodrigo de Aquino Castro, Marair Gracio Ferreira Sartori, Manoel João Batista Castello Girão

Department of Medicine, Federal University of Sao Carlos (JTNT), Sao Carlos; Ambulatory of Urogynecology, Health Secretary of Jau (RCOSC), Jau; ABC School of Medicine (JMT), Santo Andre; Department of Urogynecology and Pelvic Surgery, Department of Gynecology (PCFJr, RAC, MGFS, MJBCG), Federal University of Sao Paulo, Sao Paulo, SP, Brazil

\section{ABSTRACT}

Objective: To compare the effects of two surgical procedures for the correction of anterior vaginal wall prolapse (AVWP) on the lower urinary tract symptoms (LUTS) using symptom questionnaires and quality of life (QoL).

Materials and Methods: One hundred women with Pelvic Organ Prolapse Quantification stage (POP-Q) $\geq 2$ were randomly distributed in two preoperatory groups. The first group (mesh) $(\mathrm{n}=45)$ received a polypropylene mesh $(\mathrm{PM})$ implant and the control group $(\mathrm{n}=$ 55) was submitted to anterior colporraphy with or without synthetic sling. Postoperatory follow-up was done after 12 months. The primary objective was to compare the effect of the surgeries on LUTS using the final scores of the International Consultation on Incontinence Questionnaire Urinary Incontinence Short Form (ICIQ-UI SF) and Overactive Bladder Questionnaire (OAB-V8), as well as the analysis of the incapacitating urinary symptoms and "de novo" urinary symptoms after 12 months of surgery in both groups.

Results: Although there was a different number of women in each group, randomization was adequate, resulted in homogeneous groups that could be compared regarding socio demographic, clinical and gynecological (POP-Q) variables. Patients of both groups showed improvements regarding LUTS and QoL, whether using polypropylene mesh or not, based on the final scores of the ICIQ-UI SF and OAB-V8 questionnaires after 12-month follow-up. There were few incapacitating and "de novo" urinary symptoms, without any significant statistical difference between both groups after 12 months of surgery.

Conclusion: There was a general improvement of LUTS and QoL in both groups after 12-month follow-up. However, there was no significant difference of LUTS, as well as the more incapacitating and "de novo" urinary symptoms between both groups after 12 months of surgery.

\section{ARTICLE INFO}

\section{Key words:}

Prolapse; Therapeutics;

Quality of Life; Pelvic Floor

Disorders

Int Braz J Urol. 2013; 39: 531-41

Submitted for publication:

December 21, 2012

Accepted after revision:

April 19, 2013

\section{INTRODUCTION}

The decision to perform a prophylactic anti-incontinence surgery in women with suspi- cion of a hidden stress urinary incontinence (SUI) during a surgery for correction of pelvic organ prolapse (POP) is controversial. At present, this approach has been recommended during evaluation of 
hidden urinary stress incontinence at pre-operatory period (1). However, this evaluation not always identifies correctly women who need prophylactic anti-incontinence surgery during correction of anterior vaginal wall prolapse (AVWP) (2). The use of polypropylene mesh (PM) in surgeries for genital dystopia has been popularized in the last years, throughout standardization of the surgical technique, with good anatomical results in short and medium terms. However, based on the recent reports of complications related to the use of mesh in those surgeries, the Food and Drug Administration (FDA) has been warning surgeons about the complications of the use of polypropylene mesh in vaginal reconstructive surgeries (3). In view of the relative low number of publications about this subject, we proposed a comparative study between both surgical techniques for AVWP correction, analyzing the results regarding lower urinary tract symptoms (LUTS).

\section{MATERIALS AND METHODS}

\section{Study Design, objectives and patient selection}

This is a prospective, randomized, single-blinded and controlled study to evaluate the outcomes of two surgical procedures to correct AVWP. The evaluation of the anatomical cure (POP-Q) and complications will be discussed separately (Part I).

From February 2008 to December 2010, 122 women attending the Ambulatory of Urogynecology, Health Secretary of Jau, SP, Brazil, were selected. Women 45 years old or older, with AVWP $\geq$ II (POP-Q Stage) (4) without previous surgical correction or with previous surgical treatment of AVWP without the use of PM were selected. Exclusion criteria were women receiving oncological treatment with altered Papanicolau Smear exam or with uterine bleeding, with genital or acute urinary infection, patients who did not commit to ambulatory follow-up or those that refused the written informed consent.

Patients, study location and eligibility criteria Methods, definitions and units were used according to the standards of the International Continence Society (ICS) and Internatio- nal Urogynecology Association (IUGA) (5). Data included age (years), parity, number of deliveries, body mass index (BMI - $\mathrm{Kg} / \mathrm{m} 2$ ), hormonal status (pre-, peri and postmenopausal), history of previous histerectomy (yes or no) and POP stage (POP-Q). Clinical categories were used to evaluate the hormonal status. Women with more than 12 months of amenorrhea were considered in the post-menopausal period. Analysis of lower urinary tract symptoms included SUI, urge-incontinence, frequency and voiding difficulty. The study was approved by the Ethical Committee of the Federal University of Sao Paulo - UNIFESP - under the number 1335/08.

The same group of authors idealized, developed and conducted all steps of the study, including follow-up. PM supplies did not donate funds or surgical devices samples for the study.

\section{Evaluations \\ Objective:}

POP-Q was used to measure (in centimeters) the supporter of several anatomical aspects of the vaginal canal (4);

\section{Urinary Incontinence Evaluation}

Objective: During preoperatory period, patients were submitted to urodynamic evaluation (Dynapack MPX 816, Dynamed, Sao Paulo, Brazil) including spontaneous uroflowmetry, cystometry, pressure/flow studies and post-voiding residue. SUI was analyzed at the end of cystometry, with a reasonable full bladder. SUI was considered in the event of any urinary loss during straining. The same maneuver was repeated after reduction of AVWP and placement of a gauze tampon deep in the vagina in order to verify hidden urinary incontinence (2). Idiopathic detrusor overactivity (ID0) was considered in the presence of spontaneous or elicited involuntary detrusor contractions during cystometry. Urodynamics evaluation followed the recommendations of the Urodynamic Society (6).

\section{Subjective:}

International Consultation on Incontinence Questionnaire - Urinary Incontinence Short Form (ICIQ-UI SF): This is a self- 
-administered questionnaire, translated and validated for Portuguese that evaluates the impact of UI on quality of life (QoL). The first three questions evaluate frequency, severity and urinary incontinence impact on QoL. The fourth question includes eight items related to causes or situations when UI occurs. Final score is the sum of questions 3, 4 and 5 and ranges from 0 to 21, and the impact on QoL of UI is worse as the score rises (7). The presence of SUI was evaluated through item 3 of question 4 (Do you lose urine during coughing or sneezing?).

Overactive Bladder Questionnaire - V8: This is a self-administered questionnaire, validated and translated for Portuguese with eight questions (8) that evaluates lower urinary tract symptoms and help the clinical diagnosis of overactive bladder syndrome $(\mathrm{OAB})$. Each question has a 6-point Likert scale that ranges from "never" (score $=0$ ) to "very much" (score $=6$ ). Final score varies from 0 to 48 and the higher the score, the worse the symptoms. The presence of irritative lower urinary tract symptoms like "frequency" and "urge-incontinence" was respectively evaluated through questions 1 and 8. The answers were considered positive when the patients answered "very" or "very much".

Voiding difficulty: It was evaluated through a positive answer (not, a little, moderately or much) for the question: "Do you have voiding difficulty?" using the scale of symptoms of the King's Health Questionnaire (KHQ), translated and validated for Portuguese (9).

\section{Objectives}

Primary: final scores of the ICIQ-UI SF and $\mathrm{OAB}-\mathrm{V} 8$ questionnaires after 12-month follow-up:

\section{ICIQ-UI SF}

Final score $=0$ (no UI)

Final score $\geq 3$ (presence

of UI)

\section{OAB-V8}

Final score $=0$ (no irritative low urinary tract symptoms)
Final score $\geq 1$ (presence of irritative lower urinary tract symptoms)

Secondary: Evaluation of more incapacitating urinary and "de novo" symptoms, such as frequency, voiding difficulty, urge-incontinence, and stress urinary incontinence after 12-month follow-up.

\section{Polypropylene mesh kit description NAZCA TC KIT (Promedon, Cordoba, Ar- gentina)}

NAZCA TC kit includes type 1 PM, monofilament, with macropores varying from 0.5 to 1 $\mathrm{mm}$ diameter and density of $60.5 \mathrm{~g} / \mathrm{m} 2$. PM body contains $6 \mathrm{~mm}$ diameter holes in order to facilitate integration with host tissue, lowering the amount of synthetic implanted material and local inflammatory reaction. Four self-adjustable tapes of the same material arise from the body, ending in needle connectors. Two of these tapes are passed through prepubic insertion of the needles (vaginal suprapubic route) and the other two (posterior) are passed by the needles through transobturator route. The needles reach the tendineous arcs, close to the ischial spines bilaterally (10).

\section{Surgical procedure}

All surgeries were performed under spinal anesthesia and all patients received $2 \mathrm{~g}$ of IV cephazolin for prophylaxis. Bladder catheter was inserted in the beginning of the surgery and removed in the first postoperatory day. As needed, concurrent procedures were performed, such as posterior colporraphy and vaginal hysterectomy. Patients of the control group with urodynamic diagnosis of SUI were concurrently treated with retropubic synthetic sling. All patients were operated by the same surgical team (JTNT, MMMT). Before the beginning of the study, the surgeons performed two surgeries using NAZCA TC in order to reduce the learning curve impact on the final results.

\section{NAZCA TC surgical procedure}

With the patient in the lithotomy position, a midline incision in the anterior vaginal wall is performed, from the midurethra to the uterine 
cervix. The dissection is continued until the ischial-pubic branch and inferior edge of the pubic symphysis. The needles are passed from the vaginal incision to the suprapubic region in order to allocate the prepubic tapes. After removing the handle of the needle on the vaginal side, it is reconnected on the suprapubic side of the needle. After the anterior tape of the NAZCA TC is connected, the needle is gently pulled and the maneuver is finished with the exteriorization of the anterior tape in the suprapubic region. The same maneuver is made in the other side, creating a bracket of the median urethra. The transobturator needle is passed through the genitofemoral fold $2 \mathrm{~cm}$ laterally and $3 \mathrm{~cm}$ inferiorly to the urethral meatus. This needle must reach the region close to the ischial spine, exteriorized through the vaginal incision. The posterior tapes are connected to the needle and removed, exteriorizing through the genitofemoral fold incision. This maneuver is repeated in the contralateral side. The body of the mesh is fixed with absorbable sutures in the region of the cardinal ligaments and in the region of the cervical ring. The four tapes are adjusted in order to correct AVWP without folds or material redundancy. The excess is discharged before the closure of the anterior vaginal wall incision, performed with separated sutures of Vycril 2-0 (10).

\section{Traditional anterior colporraphy}

With the patient in the lithotomy position, a midline incision on the anterior vaginal wall is performed, from the midurethra to the uterine cervix. The anterior vaginal wall is separated from the vesicovaginal fascia and from the bladder using pointless detachment. This maneuver identifies occasional lesion (relaxation or rupture) of the vesicovaginal fascia. In case of central defect it is corrected using plication of the fascia along the midline using separated sutures of Vycril 2-0. Lateral defects are treated using localized sutures with Vycril 2-0 (11).

\section{Treatment of SUI for the Control Group}

Patients from the control group with a preoperatory urodynamic diagnosis of SUI were concomitantly treated with retropubic synthetic sling (12). All patients were treated by the same surgical team, and all members had surgical experience with urogynecological procedures.

\section{Statistical analysis}

In order to evaluate preoperatory differences between both groups, chi-square test was used for cathegoric variables and t-Student test for continuous variables with normal distribution. All numerical data were expressed as mean \pm standard deviation (SD). Paired t-test was used to detect differences between pre and postoperatory periods. The significance level adopted was 5\%.

\section{Sample size calculation}

The sample size was estimated upon literature data $(1,11)$. It was expected anatomical failure after 12-month follow-up of 38\% for control group and $12 \%$ for mesh group. In order to detect this difference (bilateral test), with 0.05 level of significance and power of the test 80\%, 42 women should be allocated at least in each group. With an estimate of 10\% loss after 12-month follow-up, a total of 92 women were randomized. The sample was increased to 100 women in order to consider a $20 \%$ loss of follow-up after 24 months.

\section{Randomization and blinding}

This trial adopted single-blind masking to reduce bias derived from the knowledge of the patients about which procedure she was submitted.

Randomization based in a single sequence of random tasks is called simple randomization. This technique maintains complete randomization of a single subject in a determined group, with adequate balance, mainly in groups with more than 100 individuals (13). Randomization was made by simple raffle few minutes before surgery when the result was informed to the surgical team, in order to proceed with the designed surgery.

Women were randomly distributed in two groups: Mesh group $(M)(n=45)$ that used PM implant and Control group (C) $(n=55)$, treated with traditional anterior colporraphy \pm suburethral synthetic sling when needed.

Figure-1 shows details of patient selection, including randomization and the final number of evaluated patients after 12-month follow-up in both groups.

Concurrent surgeries were performed according patient's individual needs. Postoperatory eva- 
Figure 1 - Patient flow and randomization
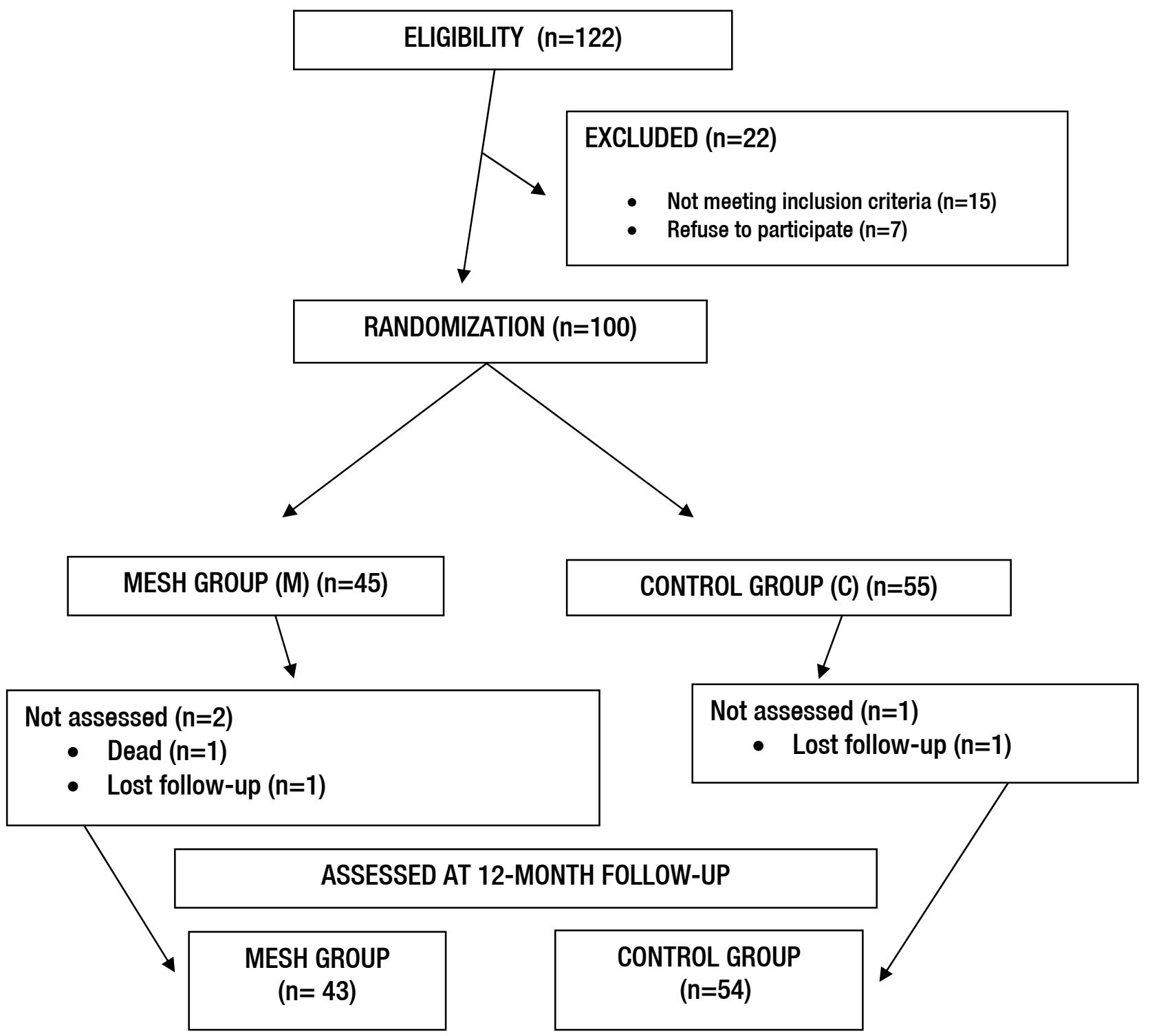

luation was performed after 12 months of surgery. The informed consent was read and signed by all patients before the beginning of the study.

\section{RESULTS}

During the preoperatory period, both groups were homogeneous regarding age, parity, number of deliveries, BMI, hormonal status, previous hysterectomy and POP stage, indicating an adequate randomization effect (Table-1). Table-2 shows the pre- and postoperatory POP-Q measures.

There was no significant statistical difference among the POP-Q measures between the groups during the preoperatory period. There was a statistically significant difference in all POP-Q values 
Table 1 - Demographic characteristics of the Mesh and Control groups during preoperatory period $(n=100)$

\begin{tabular}{|c|c|c|c|}
\hline Demographic characteristics & $\operatorname{Mesh}(n=45)$ & Control $(n=55)$ & $p$-value \\
\hline \multicolumn{4}{|l|}{ Age (years) } \\
\hline Mean (SP) & $66.8(9.2)$ & $63.4(9.5)$ & $0.08^{*}$ \\
\hline Interval (min/max) & $53-84$ & $48-84$ & \\
\hline \multicolumn{4}{|l|}{ Parity } \\
\hline Nulliparous n (\%) & $0(0)$ & $3(5.5)$ & $0.94^{*}$ \\
\hline Multiparous n (\%) & $45(100)$ & $52(94.5)$ & \\
\hline \multicolumn{4}{|l|}{ Number of deliveries } \\
\hline Mean (SD) & $4.2(2.6)$ & $4.2(2.7)$ & $0.94^{*}$ \\
\hline Interval (min/max) & $1-14$ & $0-12$ & \\
\hline \multicolumn{4}{|l|}{ BMI $\left(\mathbf{k g} / \mathbf{m}^{2}\right)$} \\
\hline Mean (SD) & $27.5(5.4)$ & $27.8(4.9)$ & $0.76^{*}$ \\
\hline Interval (min/max) & $17-42$ & 16-39 & \\
\hline \multicolumn{4}{|l|}{ Hormonal status } \\
\hline Pre-menopausal (\%) & $2(4.4)$ & $0(0)$ & $0.86^{* *}$ \\
\hline Per-menopausal (\%) & $0(0)$ & $1(0.2)$ & \\
\hline Post-menopausal (\%) & $43(95.6)$ & $54(99.8)$ & \\
\hline \multicolumn{4}{|l|}{ Previous hysterectomy } \\
\hline Yes $(\%)$ & $3(6.7)$ & $6(10.9)$ & $0.41^{* *}$ \\
\hline No $(\%)$ & $42(93.3)$ & $49(89.1)$ & \\
\hline \multicolumn{4}{|l|}{ POP stage (POP-Q) } \\
\hline II (\%) & $10(22.2)$ & $19(34.5)$ & $0.32^{\star \star}$ \\
\hline III (\%) & $28(62.2)$ & $31(56.4)$ & \\
\hline IV (\%) & $7(15.6)$ & $5(9.1)$ & \\
\hline \multicolumn{4}{|l|}{ Urodynamic parameters } \\
\hline SUI/hidden SIU (\%) & $6(13.3)$ & $12(21.8)$ & 0.40 \\
\hline Idiopathic detrusor overactivity (\%) & $26(58)$ & $35(63)$ & 0.69 \\
\hline \multicolumn{4}{|l|}{ Post-voiding urinary residual (mL) } \\
\hline Mean $( \pm$ SD) & $29(50)$ & $31(69)$ & 0.87 \\
\hline
\end{tabular}

SUI $=$ Stress urinary incontinence

Hidden SUI = Hidden stress urinary incontinence

Values $=$ mean \pm SD (standard deviation), confidence interval, frequency $(n)$, percentage $(\%)$

* Student $t$ test for independent samples

${ }^{* *}$ Qui-square test

between the pre- and postoperatory values in each particular group, demonstrating that both techniques were able to improve anatomical parameters. However, there was a significant statistically difference of the $\mathrm{Aa}$ and $\mathrm{Ba}$ points during the postoperatory period between $\mathrm{M}$ and $\mathrm{C}$ groups. Table-3 shows the results of QoL impact of UI according to the final score of ICIQ-UI SF and LUTS evaluated by the final score of $\mathrm{OAB}-\mathrm{V} 8$ at pre and postoperatory periods after 12 months. The most incapacitating effects of each surgery upon LUTS evaluated during pre- and postoperatory periods are shown at Table-4. The "de novo" symptoms of lower urinary tract in both groups after 12 months of surgery are 
Table 2 - POP-Q measurements in centimeters \pm standard deviation (SD) at pre and postoperatory periods from Mesh and Control groups

\begin{tabular}{|c|c|c|c|}
\hline & Mesh & Control & $\mathrm{p}^{\mathrm{a}}$ \\
\hline \multicolumn{4}{|l|}{ Aa } \\
\hline Pre-op & 1.47 (1.61) & $1.38(1.78)$ & 0.81 \\
\hline Post-op & $-2.39(0.82)$ & $-1.59(1.01)$ & $<0.0001$ \\
\hline$p^{b}$ & $<0.0001$ & $<0.0001$ & \\
\hline \multicolumn{4}{|l|}{$\mathrm{Ba}$} \\
\hline Pre-op & $3.38(2.50)$ & $2.55(2.50)$ & 0.10 \\
\hline Post-op & $-2.46(0.70)$ & $-1.57(1.04)$ & $<0.0001$ \\
\hline$p^{b}$ & $<0.0001$ & $<0.0001$ & \\
\hline \multicolumn{4}{|l|}{ C } \\
\hline Pre-op & $-1.44(5.10)$ & $-1.56(4.90)$ & 0.90 \\
\hline Post-op & $-6.44(1.14)$ & $-6.70(1.34)$ & 0.32 \\
\hline$p^{b}$ & $<0.0001$ & $<0.0001$ & \\
\hline \multicolumn{4}{|l|}{ D } \\
\hline Pre-op & $-2.78(5.54)$ & $-3.80(4.89)$ & 0.36 \\
\hline Post-op & $-7.6(0.66)$ & $-7.8(1.30)$ & 0.84 \\
\hline$p^{b}$ & $0.0006^{c}$ & $<0.0001$ & \\
\hline \multicolumn{4}{|l|}{ Ap } \\
\hline Pre-op & $-0.58(1.87)$ & $-0.67(1.97)$ & 0.81 \\
\hline Post-op & $-2.74(0.66)$ & $-2.67(1.34)$ & 0.74 \\
\hline $\mathrm{p}^{\mathrm{b}}$ & $<0.0001$ & $<0.0001$ & \\
\hline \multicolumn{4}{|l|}{ Bp } \\
\hline Pre-op & $0.42(3.33)$ & $0.18(2.90)$ & 0.70 \\
\hline Post-op & $-2.74(0.66)$ & $-2.79(0.53)$ & 0.69 \\
\hline$p^{b}$ & $<0.0001$ & $<0.0001$ & \\
\hline \multicolumn{4}{|c|}{ GH (genital hiatus) } \\
\hline Pre-op & $4.70(1.10)$ & $4.80(1.30)$ & 0.65 \\
\hline Post-op & $2.63(0.69)$ & $2.76(0.64)$ & 0.34 \\
\hline$p^{b}$ & $<0.0001$ & $<0.0001$ & \\
\hline
\end{tabular}


continuation

\section{PB (perineal body)}

$\begin{array}{lccc}\text { Pre-op } & 2.70(0.84) & 2.70(0.77) & 0.71 \\ \text { Post-op } & 4.00(0.62) & 4.04(0.77) & 0.80 \\ p^{b} & <0.0001 & <0.0001 \\ \text { L (total vaginal length) } & & 9.40(1.03) & 0.81 \\ \text { Pre-op } & 9.35(1.04) & 8.69(1.47) & 0.08 \\ \text { Post-op } & 8.23(0.87) & <0.0001 & \end{array}$

$\mathbf{P O P}-\mathbf{Q}=$ Pelvic organ prolapse quantification

a Student t test for independent samples

b Student $t$ test for paired samples

c Student $t$ test for paired samples (analysis of patients with point $D$ after the surgery)

Table 3 - Evaluation of final scores of ICIQ-UI SF and OAB-V8 questionnaires at the pre- and postoperatory periods of patients from Mesh and Control groups. Values presented as mean \pm SD.

\begin{tabular}{lccc}
\hline & Mesh & Control & $p^{\mathrm{a}}$ \\
\hline ICIQ-UI SF Final score (0-21 interval) & & & \\
Preop & $9.2( \pm 8.4)$ & $11.2( \pm 7.6)$ & 0.22 \\
Postop & $3.5( \pm 5.1)$ & $4.6( \pm 6.3)$ & 0.36 \\
$p^{\text {b }}$ & 0.0003 & $<0.0001$ & \\
OAB-V8 Final score (0-48 interval) & & & \\
Preop & $14.95( \pm 12.37)$ & $20.38( \pm 12.56)$ & 0.03 \\
Postop & $3.3( \pm 6.2)$ & $6.2( \pm 8.8)$ & 0.07 \\
$p^{\text {b }}$ & $<0.0001$ & $<0.0001$ & \\
\hline
\end{tabular}

ICIQ-UI SF = International Consultation on Incontinence Questionnaire - Urinary Incontinence Short Form

OAB-V8 = Overactive Bladder Questionnaire - V8

a t Student test for independent samples

b $t$ Student test for paired samples

shown at Table-5. One patient of the M group and two patients of the $\mathrm{C}$ group had SUI in the initial postoperatory period and all were treated with a retropubic synthetic sling, and all were considered cured based upon subjective evaluation after 12 months of surgery.

\section{DISCUSSION}

During the preoperatory period, both groups were homogeneous regarding age, parity, number of deliveries, BMI, hormonal status, previous hysterectomy and POP stage, indicating an adequate 
Table 4 - Surgery effect on the most incapacitating lower urinary tract symptoms comparing pre- and postoperatory periods after 12 months of Mesh and Control groups. Values expressed as frequency and percentage (\%).

\begin{tabular}{lcccccc}
\hline $\begin{array}{l}\text { Lower urinary tract } \\
\text { most incapacitating } \\
\text { symptoms }\end{array}$ & \multicolumn{2}{c}{$\begin{array}{c}\text { Group Mesh } \\
\mathrm{n}(\%)\end{array}$} & \multicolumn{4}{c}{$\begin{array}{c}\text { Group Control } \\
\mathrm{n}(\%)\end{array}$} \\
\hline & $\begin{array}{c}\text { Pre-operatory } \\
(\mathrm{n}=45)\end{array}$ & $\begin{array}{c}12 \text {-month postopera- } \\
\text { tory }(\mathrm{n}=43)\end{array}$ & $\mathrm{P}^{*}$ & $\begin{array}{c}\text { Pre-opera- } \\
\text { tory }(\mathrm{n}=55)\end{array}$ & $\begin{array}{c}12 \text {-month posto- } \\
\text { peratory }(\mathrm{n}=54)\end{array}$ & $\mathrm{P}^{*}$ \\
Frequency & $20(44.4)$ & $5(11.6)$ & 0.0015 & $27(49.1)$ & $7(12.9)$ & 0.0001 \\
Voiding difficulty & $6(13.3)$ & $0(0.0)$ & 0.0396 & $11(20)$ & $0(0)$ & 0.0016 \\
$\begin{array}{l}\text { Urge-urinary } \\
\text { incontinence }\end{array}$ & $22(48.9)$ & $7(16.3)$ & 0.0025 & $30(54.4)$ & $8(14.8)$ & $<0.0001$ \\
SUI & $8(17.8)$ & $0(0.0)$ & 0.0100 & $12(21.8)$ & $1(1.8)$ & 0.0035 \\
\hline
\end{tabular}

* Student $t$ test for paired samples

Table 5 - Surgery effect on "de novo" lower urinary tract symptoms after 12-month follow-up, in Mesh and Control groups. Values expressed in frequency and percentage (\%).

\begin{tabular}{lccc}
\hline "De novo" incapacitating lower urinary tract symptoms & $\begin{array}{c}\text { Mesh } \\
(\mathrm{n}=43)\end{array}$ & $\begin{array}{c}\text { Control } \\
(\mathrm{n}=54)\end{array}$ & $\mathrm{P}^{*}$ \\
\hline Frequency & $2(4.6)$ & $3(5.5)$ & 0.7933 \\
Voiding difficulty & $0(0)$ & $0(0)$ & 1.0000 \\
Urge-urinary incontinency & $1(2.3)$ & $4(7.4)$ & 0.5078 \\
Stress urinary incontinency & $2(4.6)$ & $3(5.5)$ & 0.7723 \\
\hline
\end{tabular}

*Student $t$ test for paired samples

randomization effect (Table-1). Table-2 shows the pre- and postoperatory POP-Q measures.

There was no significant statistical difference among the POP-Q measures between the groups during the preoperatory period. There was a statistically significant difference in all POP-Q values between the pre- and postoperatory values in each particular group, demonstrating that both techniques were able to improve anatomical parameters. However, there was a significant statistically difference of the $\mathrm{Aa}$ and $\mathrm{Ba}$ points during the postoperatory period between $\mathrm{M}$ and $\mathrm{C}$ groups.
Table-3 shows the results of QoL impact of UI according to the final score of ICIQ-UI SF and LUTS evaluated by the final score of OAB-V8 at pre and postoperatory periods after 12 months. The most incapacitating effects of each surgery upon LUTS evaluated during pre- and postoperatory periods are shown at Table-4. The "de novo" symptoms of lower urinary tract in both groups after 12 months of surgery are shown at Table-5. One patient of the $\mathrm{M}$ group and two patients of the $\mathrm{C}$ group had SUI in the initial postoperatory period and all were treated with a retropubic synthetic sling, and 
all were considered cured based upon subjective evaluation after 12 months of surgery.

\section{CONCLUSIONS}

Although the anatomical rate cure of the AVWP was superior in the group treated with polypropylene mesh after 12 months of surgery, this significant anatomical difference did not result in a subjective difference of the presence of LUTS. Both procedures were able to improve LUTS, with low rate of "de novo" urinary symptoms.

\section{ACKNOWLEDGMENTS}

POP = Pelvic organ prolapse

AVWP $=$ Anterior vaginal wall prolapse

$\mathrm{PM}=$ Polypropylene mesh

SUI $=$ Stress urinary incontinence

POP-Q = Pelvic Organ Prolapse Quantification

ICS = International Continence Society

IUGA = International Urogynecology Association

ICI-RS = International Consultation on Incontinence

- Research Society

KHQ = King's Health Questionnaire

BMI = Body mass index

ICIQ-VS = International Consultation on Incontinence Questionnaire - Vaginal Symptoms

ICIQ-UI SF = International Consultation on Incontinence Questionnaire Urinary Incontinence Short Form

OAB-V8 = Overactive Bladder Questionnaire - short version with 8 questions

QoL = Quality of life

$\mathrm{M}=$ Mesh group

$\mathrm{C}=$ Control group

$\mathrm{SD}=$ Standard deviation

FDA = Food and Drug Administration

$\mathrm{UI}=$ Urinary incontinence

$\mathrm{OAB}=$ Overactive bladder

IDO = Idiopathic detrusor overactive

\section{CONFLICT OF INTEREST}

None declared.

\section{REFERENCES}

1. Maher CM, Feiner B, Baessler K, Glazener CM: Surgical management of pelvic organ prolapse in women: the updated summary version Cochrane review. Int Urogynecol J. 2011; 22: $1445-57$

2. Svenningsen R, Borstad E, Spydslaug AE, Sandvik L, Staff AC: Occult incontinence as predictor for postoperative stress urinary incontinence following pelvic organ prolapse surgery. Int Urogynecol J. 2012; 23: 843-9.

3. Menchen LC, Wein AJ, Smith AL: An appraisal of the Food and Drug Administration warning on urogynecologic surgical mesh. Curr Urol Rep. 2012; 13: 231-9.

4. Bump RC, Mattiasson A, Bø K, Brubaker LP, DeLancey JO, Klarskov $P$, et al.: The standardization of terminology of female pelvic organ prolapse and pelvic floor dysfunction. Am J Obstet Gynecol. 1996; 175: 10-7.

5. Haylen BT, de Ridder D, Freeman RM, Swift SE, Berghmans $B$, Lee J, et al:: An International Urogynecological Association (IUGA)/International Continence Society (ICS) joint report on the terminology for female pelvic floor dysfunction. Neurourol Urodyn. 2010; 29: 4-20.

6. Blaivas JG, Appell RA, Fantl JA, Leach G, McGuire EJ, Resnick NM, et al.: Definition and classification of urinary incontinence: recommendations of the Urodynamic Society. Neurourol Urodyn. 1997; 16: 149-51.

7. Tamanini JT, Dambros M, D'Ancona CA, Palma PC, Rodrigues Netto N Jr: Validation of the "International Consultation on Incontinence Questionnaire -- Short Form" (ICIQ-SF) for Portuguese. Rev Saude Publica. 2004; 38: 438-44.

8. Acquadro C, Kopp Z, Coyne KS, Corcos J, Tubaro A, Choo MS, et al.: Translating overactive bladder questionnaires in 14 languages. Urology. 2006; 67: 536-40. Erratum in: Urology. 2007; 69: 202. Oh, Seung June [added].

9. Tamanini JT, D’Ancona CA, Botega NJ, Rodrigues Netto N Jr: Validation of the Portuguese version of the King's Health Questionnaire for urinary incontinent women. Rev Saude Publica. 2003; 37: 203-11.

10. Palma P, Riccetto C, Prudente A, Dalphorno F, Delroy C, Castro $\mathrm{R}$, et al.: Monoprosthesis for anterior vaginal prolapse and stress urinary incontinence: midterm results of an internationalmulticentre prospective study. Int Urogynecol J. 2011; 22: 1535-41.

11. Feldner PC Jr, Castro RA, Cipolotti LA, Delroy CA, Sartori MG, Girão MJ: Anterior vaginal wall prolapse: a randomized controlled trial of SIS graft versus traditional colporrhaphy. Int Urogynecol J. 2010; 21: 1057-63.

12. Palma PC, Riccetto CL, Dambros M, Thiel M, de Fraga R, Tamanini JT, et al.: SAFYRE. A new concept for adjustable minimally invasive sling for female urinary stress incontinence. Actas Urol Esp. 2004; 28: 749-55. 
13. Suresh K: An overview of randomization techniques: An unbiased assessment of outcome in clinical research. J Hum Reprod Sci. 2011; 4: 8-11.

14. Adile B, Gugliotta G, Adile G, Lo Verso L, Sommatino F, Scurria S: Monoprosthesis for simultaneous correction of stress urinary incontinence and cystocele: a 3-year follow-up. Urologia. 2012; 79(Suppl 19): 134-7.

15. de Boer TA, Vierhout ME: Predictors for overactive bladder symptoms after pelvic organ prolapse surgery. Curr Opin Obstet Gynecol. 2011; 23: 366-70.

16. de Boer TA, Salvatore S, Cardozo L, Chapple C, Kelleher C, van Kerrebroeck $P$, et al.: Pelvic organ prolapse and overactive bladder. Neurourol Urodyn. 2010; 29: 30-9.

17. Goldman HB: SUI surgery at the time of vaginal POP repair: is a surgical algorithm possible or desirable? Neurourol Urodyn. 2011; 30: 758-61.
18. Wei JT, Nygaard I, Richter HE, Nager CW, Barber MD, Kenton $\mathrm{K}$, et al.: A midurethral sling to reduce incontinence after vaginal prolapse repair. N Engl J Med. 2012; 366: 2358-67.

19. Adams SR, Dramitinos P, Shapiro A, Dodge L, Elkadry E: Do patient goals vary with stage of prolapse? Am J Obstet Gynecol. 2011; 205: 502. e1-6.

Correspondence address: Dr. José Tadeu Nunes Tamanini Departamento de Medicina / Universidade Federal de São Carlos - UFSCar Rodovia Washington Luís, km 235 - SP-310 São Carlos, SP, 13565-905, Brazil E-mail: tadeutamanini@ufscar.br 